\title{
Erratum to: Modified veneer bone graft with the concomitant installation of a dental implant: technical note
}

\author{
Seong-Gon Kim • Ji-Young Song • Yong-Chan Lee
}

Published online: 17 May 2011

(C) Springer-Verlag 2011

Erratum to: Oral Maxillofac Surg

DOI 10.1007/s10006-011-0271-z

The author wishes to apologize for inadvertently providing the wrong image for Fig. 2. Here is the correct image:

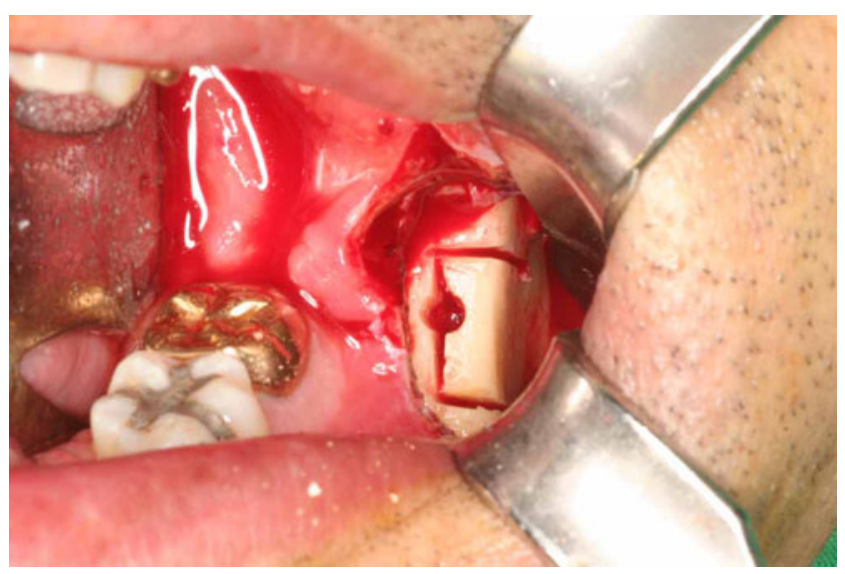

Fig. 2 Using a sagittal saw, three osteotomy lines were designed on the outer cortical bone

The online version of the original article can be found at $\mathrm{http}: / \mathrm{dx}$.doi.org/ 10.1007/s10006-011-0271-z.

S.-G. Kim $(\bowtie) \cdot$ J.-Y. Song

Department of Oral and Maxillofacial Surgery,

College of Dentistry, Gangneung-Wonju National University,

Gangneung, Gangwondo 210-702, Republic of Korea

e-mail: epker@chol.com

Y.-C. Lee

Department of Oral and Maxillofacial Surgery, Bestian Hospital,

Seoul, Republic of Korea 